\title{
A Paleoeskimo Occupation on Southern Banks Island, N.W.T.
}

\author{
CHARLES D. ARNOLD'
}

\begin{abstract}
Significant changes occurred within Paleoeskimo cultures during the first millenium B.C. Archaeological remains from the Lagoon site, on Banks Island, N.W.T., provide a new perspective on the nature of those changes and insights into some of the processes involved.
\end{abstract}

\begin{abstract}
RÉSUMÉ. Des changements significatifs se sont produits au sein des cultures paléoesquimaudes au cours du premier millénaire avant notre ère. Les vestiges archéologiques recueillis au site Lagoon, sur l'île Banks, T.N.O., sont liés à ces changements culturels. Les donnees de ce site nous fournissent un nouvel aperçu de ces changements de même qu'elles nous renseignent sur quelques-uns des processus impliqués dans ces ajustements culturels.
\end{abstract}

Traduit par Ian Badgley, Université du Québec à Montréal.

\section{INTRODUCTION}

Over the past few decades, archaeologists working in the North American Arctic have fleshed out a culture history that, early in the century, had been periodized into Paleoeskimo and Neoeskimo stages (Steensby, 1916). As data accumulated, two sub-cultural areas emerged and took on definition. One of these is arctic Alaska. The second is the eastern Canadian Arctic, possibly with a core area in the Foxe Basin-Hudson Strait region (Maxwell, 1976). The Banks Island Archaeological Research Project was formulated as a research tool with which to investigate the prehistory of a region intermediate to these sub-culture areas. The focus of the project during the 1976 and 1977 field seasons was the Lagoon site (OjR1-3), a fourth or fifth century B.C. Paleoeskimo occupation (Arnold, 1978). The archaeological remains from the site are of interest as they exhibit characteristics which strain existing typological-historical frameworks. In doing so, they provide insights into processes of cultural change that may have widespread applicability to the interpretation of arctic prehistory.

THE LAGOON SITE

The Lagoon site was discovered in 1976 during a reconnaissance of the lower Masik River valley and adjacent coastline of southwestern Banks Island, N.W.T. (Fig. 1). A combination of factors make this area suitable for human occupation. A wide, flat glacial outwash plain at the mouth of the Masik River, which merges with a sandy beach, stands in contrast to the steep hills and sea cliffs which converge upon the ocean further along the coast. The attraction of the beach is enhanced by the fact that it collects driftwood which washes over from the Mackenzie Delta. Seals are plentiful in the offshore waters and, although rare, walrus and bowhead whales are known to occur. Waterfowl 


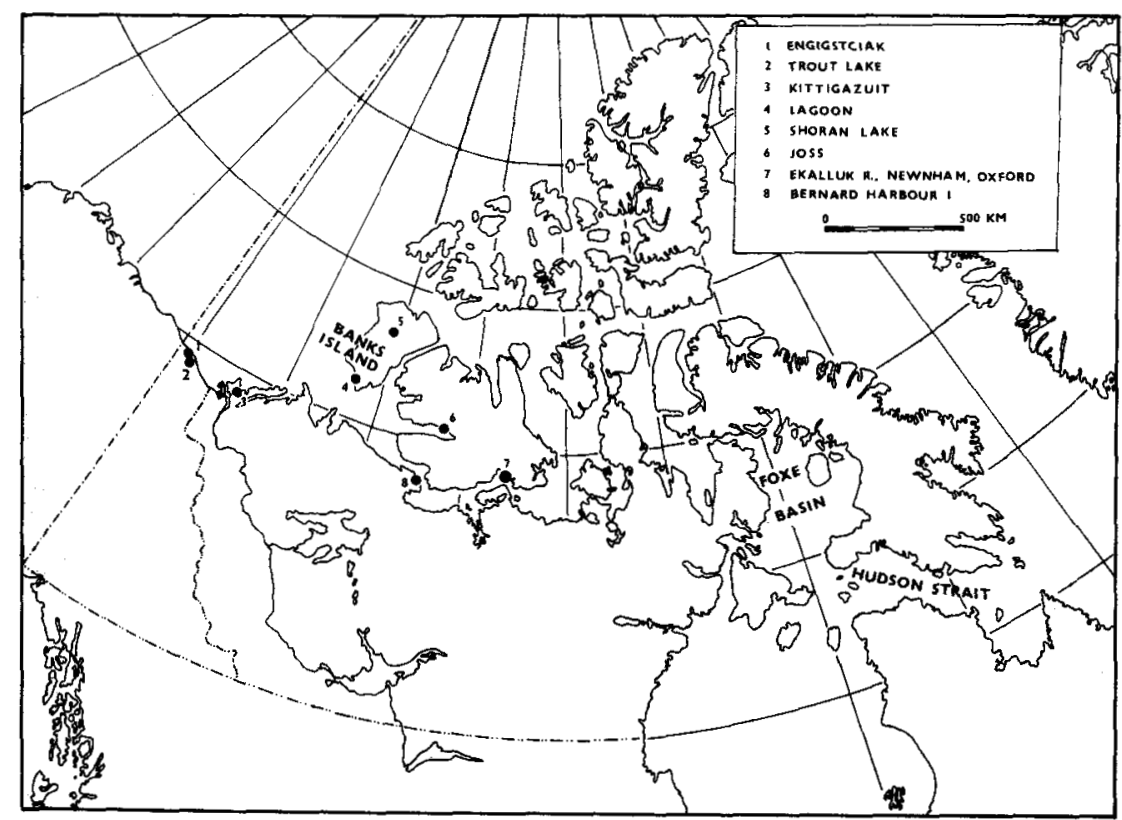

FIG. 1. Archaeological sites and locations mentioned in text.

abound, many of which nest along the margins of small tundra ponds which dot the terrain. Small groups of Peary caribou are occasionally seen; more common are muskoxen, which appear to have played a major role in the economics of most prehistoric inhabitants of the island (Taylor, 1967; Schledermann et al., 1975).

\section{Site Description}

The Lagoon site is situated approximately $3 \mathrm{~km}$ southeast of the Masik River. It extends intermittently for several hundred meters along the island shore of a saltwater lagoon, with cultural debris concentrated in several discrete areas. Excavations were conducted at three of these localities, designated as areas A, $B$, and $C$ (Fig. 2).

Area $\mathrm{C}$ was characterized by a surface exposure of lithic debris and a few broken tools, and seemed to be associated with the butchered remains of two muskoxen located nearby. Area B contained a buried cultural component currently being eroded by the lagoon. The large quantity of faunal remains concentrated within the $13 \mathrm{~m}^{2}$ excavated in this area may have been the remnant of a midden once associated with a dwelling which has since been washed away by the lagoon. This observation is extrapolated from the nature of the cultural deposits in Area A, where dwelling remains with associated midden areas were encountered, and which served as the focal point of archaeological inquiry at the site.

The presence of a buried cultural deposit in Area A was first brought to our attention by artifacts which had been exposed on the surface through processes 


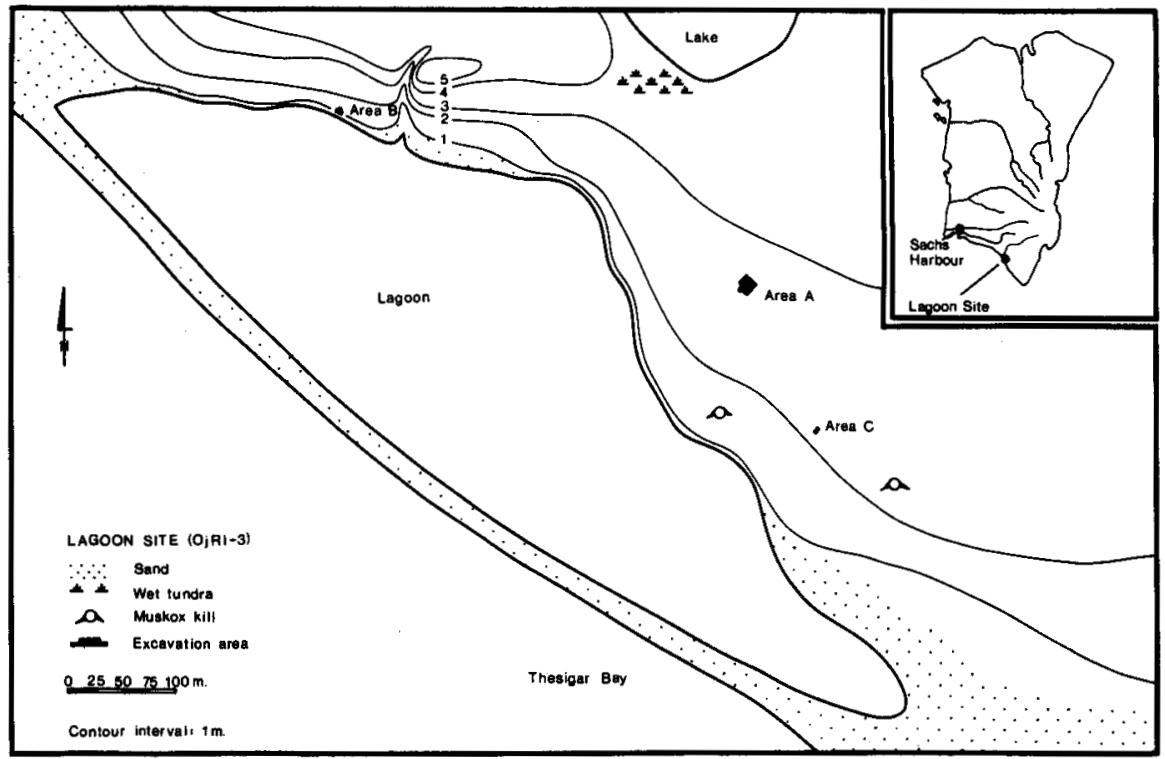

FIG. 2. The Lagoon site, showing excavation areas.

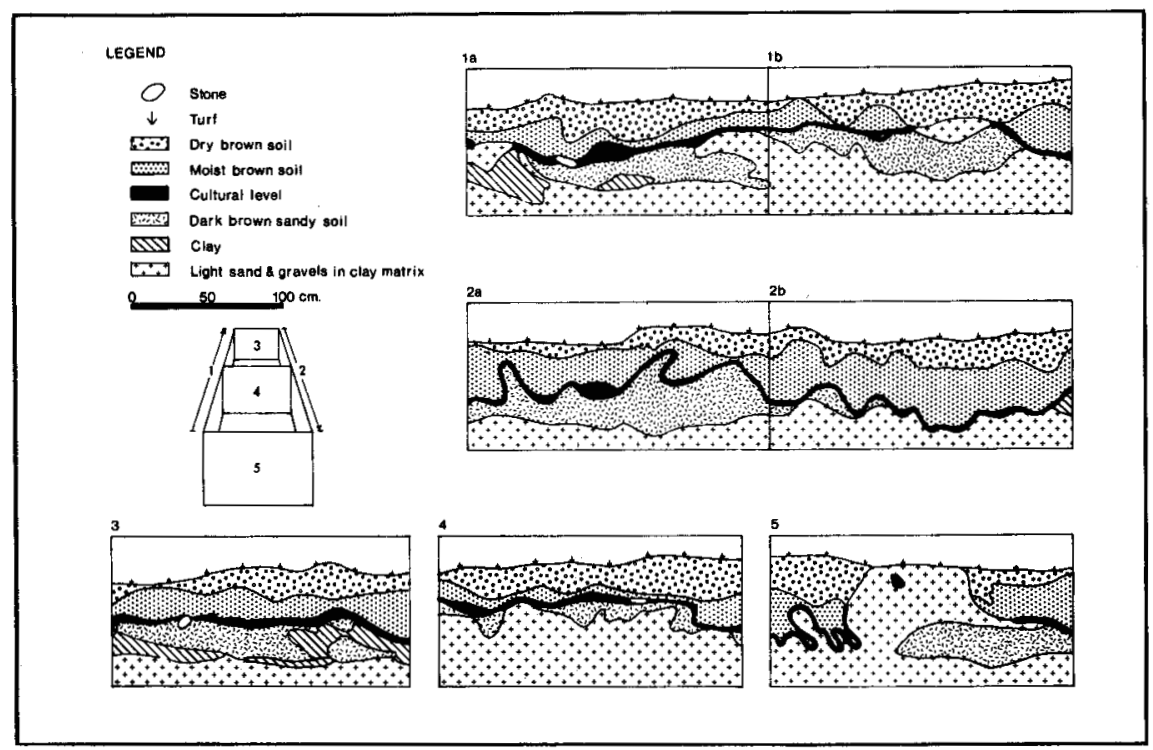

FIG. 3. Profiles on a $2 \mathrm{~m} \times 2 \mathrm{~m}$ trench in Area A.

of soil displacement originating in the frozen substratum. Reigar (1975:754) notes that heaving and thrusting in wet soils overlying permafrost can result in circular areas of bare ground up to two metres across which commonly exhibit some degree of sorting of stones and gravels. Patches of bare ground meeting this 
description are common in Area A, and it was around the margins of these that cultural material was exposed.

An examination of the stratigraphic profiles of two adjacent $2 \times 2 \mathrm{~m}$ excavation units serves to illustrate the genesis of these formations (Fig. 3). The cultural layer appeared as a discrete lens of compacted soil, discoloured by charcoal and greasy in texture, which varied from less than $1 \mathrm{~cm}$ to greater than $10 \mathrm{~cm}$ in thickness. This was overlain by Arctic Brown soil, which was stabilized by the vegetation cover. In most areas, the cultural layer was underlain with deposits of sandy soil and clay; elsewhere it lay directly on a basilar stratum of sand and light gravels held in a clay matrix. The strata were convoluted and in places inverted due to hydraulic movements which had originated in the active layer during periods of thaw. Also affecting these configurations were movements of the basilar stratum which, because of its ability to hold water, had been displaced due to freezing, often to the extent that it had thrust through the overlying strata to be exposed on the surface as the bare patches noted above (Fig. 3, profile 5).

Thirty-two $2 \times 2 \mathrm{~m}$ units were excavated in Area A. The cultural material encountered had likely undergone some degree of displacement due to soil movements, but on the whole seemed to be distributed in close proximity to the 9 or 10 hearth areas that were identified. The best preserved of the hearths consisted of a shallow depression $c a .20 \mathrm{~cm}$ deep and $60 \mathrm{~cm}$ in diameter which was partially filled with and surrounded by boulders ranging up to $40 \mathrm{~cm}$ in diameter (Fig. 4). Fire-cracked rocks were scattered about, but in a fairly restricted area. The truncated remains of three driftwood posts were set into the living floor in what could have been the corner positions of a $1.6 \times 3.0 \mathrm{~m}$ rectangle enclosing the hearth. No such remains were found at a fourth hypothetical corner, and convolutions of the soil at that point precluded the preservation of a postmould. This feature conceivably served as the hearth area and structural supports for a dwelling; alternatively, the posts may have been part of a cooking, drying or smoking rack. At least two of the other hearth areas were associated with similar post remains.

ARTIFACT ANALYSIS

As the artifacts from Areas A, B, and C represent a fairly homogeneous sample, they have been grouped together for description.

\section{LITHIC ARTIFACTS}

Lithic implements $(\mathrm{N}=334)$ account for $61.7 \%$ of the 541 artifacts recovered from the Lagoon site. All but 12 are of chipped stone. A grey metamorphosed quartzite is the prominent raw material in the chipped stone class $(\mathbf{N}=273$, or $\mathbf{8 4 . 8 \%}$ of the chipped stone implements), followed by cherts of various colours $(\mathrm{N}=37$, or $11.5 \%)$, a black fine-grained quartzitic material $(\mathrm{N}=3$, or $0.9 \%)$, basalt ( $\mathrm{N}=3$, or $0.9 \%$ ), silicous siltstones $(\mathrm{N}=3$, or $0.9 \%$ ), and chalcedony $(\mathrm{N}=2$, or $0.6 \%$ ). All occur locally, although chert and chalcedony have only been observed in the form of small pebbles. The 12 remaining lithic implements 


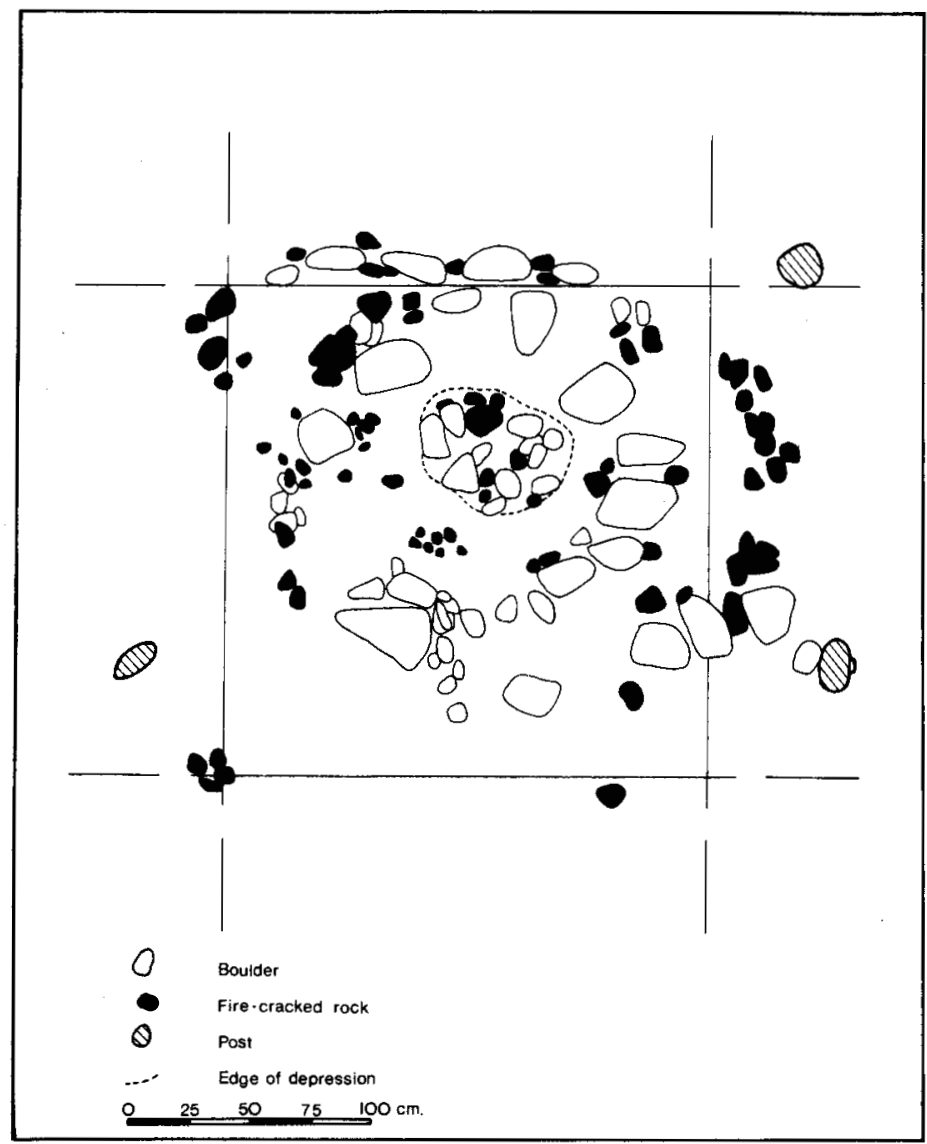

FIG. 4. Details of hearth in Area A.

have been fashioned by means other than chipping from granites, sandstone, siltstone, and mudstone, all of which occur locally.

The lithic implements are classified into functional categories on the basis of morphology, analogy, and, where applicable, upon wear patterns.

Marginally-retouched flakes $(N=28)$

This category consists of flakes and blades which exhibit varying degrees of marginal retouch. On most, the retouch is continuous along more than one edge, and appears to have been directed towards modifying the edge angle rather than the outline of the artifact. Some of these implements resemble the 'flake knives' found at Cape Denbigh, which Giddings (1964:223) suspected were used in cutting and whittling activities.

Twenty-two quartzite and three chert tools in this category have been fashioned from thin flakes. The edges that have been retouched range from concave to convex, and edge angles are shallow $\left(<45^{\circ}\right)$. Three specimens have been modified from quartzite blades (Figure 5:a). Two are relatively thick, and on these retouch has resulted in steep $\left(>45^{\circ}\right)$ edge angles. 
Scrapers $(N=47)$

Four varieties of scraping tools are recognized:

1. End scrapers $(\mathrm{N}=38)$

Twenty-three complete and 12 broken artifacts show evidence of having been hafted and used as a kind of end scraper usually associated with hide working (Levitt, 1976). With the exception of a single chert fragment, quartzite has been used as the raw material. One specimen has a flared end with projecting 'ears' (Fig. 5:b). The remainder conform to a teardrop shape: widest at the scraping (distal) end, and with straight or slightly convex margins which converge toward a narrow bulbar end (Figure 6:a). Most have been fabricated from thick flakes, thus allowing for relatively long and steep working edges. Lengths vary almost continuously from $23.9 \mathrm{~mm}$ to $61.5 \mathrm{~mm}$. In contrast, maximum widths - which usually occur at the scraping end - cluster at $c a .20 \mathrm{~mm}$. As a result, length: width ratios range from 1.1:1 (i.e. triangular, Figure $5: c$ ) to 2.6:1 (i.e. elongate, as shown in Figure 6:a). With reference to the bulbar portion of these tools, it

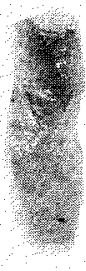

a

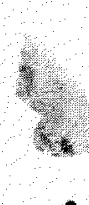

0

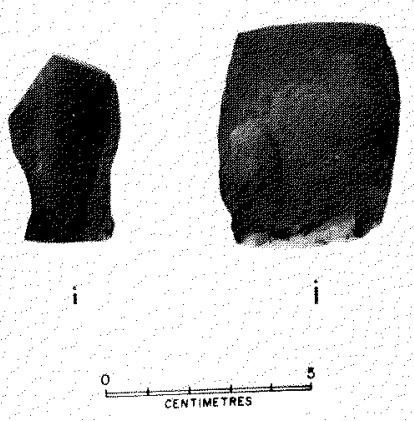

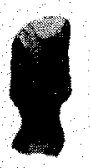

d

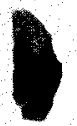

h

g

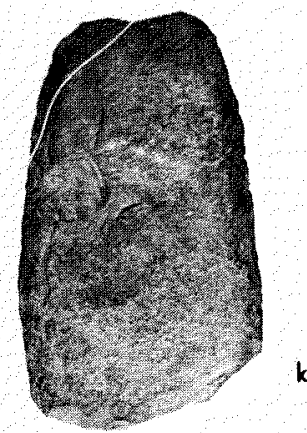

FIG. 5. Lithic artifacts; a, flake knife; b, c, end scrapers; $d$, side scraper; $e$, transverse scraper; $f$, notch; $\mathrm{g}, \mathrm{h}$, burins; i, burin-like tool; j, k, adze blades. 
appears that a few 'standard' sizes are represented, perhaps an indication that they were shaped to fit existing hafts. Grinding is prominent along the lateral edges of 20 of the specimens and discernible on most of the others.

In addition, a chert and two quartzite flakes display steep unifacial retouch along their distal ends. If these are not unfinished forms, they may have served as non-hafted end scrapers.

\section{Side scrapers $(N=3)$}

Attributes of two unifacially-worked artifacts suggest their use as end-hafted side scrapers or knives. The specimen shown in Figure $5: \mathrm{d}$ has been fashioned from a thin basalt flake. It exhibits marginal retouch along its lateral and proximal edges, is asymmetric in outline, and has two laterally-opposed side notches. Due to its asymmetric cross-section, both steep and shallow edge angles have been formed (Figure 6:b). A similar tool has been fashioned from chert. A third side scraper has been bifacially worked from quartzite, and has a stem or tang distal to the working edges.

\section{Transverse scrapers $(N=4)$}

Included here are a single quartzite and three chert unifacially-flaked, stemmed artifacts with working edges diagonal to the median line (Figs. 5:e, 6:c). The chert specimens have been made from relatively thick flakes, resulting in steep edge angles. No attempt has been made to thin the bases of these artifacts, although the lateral margins of the stems have been ground (this hafting mode occurs on several other kinds of tools as well). The quartzite specimen has been shaped from a relatively thin flake and displays marginal retouch only.

4. Notches $(\mathrm{N}=2)$

Figure 5:f is a chert flake which has been truncated at its distal end by a burin blow. The lateral margins exhibit steep retouch, and one edge has been notched. The notch is the only portion of the artifact which exhibits use-polish, and the implement is presumed to have served as a scraper for shafts and the like. A bifacially-worked chert piece, also with a single notch indented into one lateral margin, may have served a similar function. The distal edges of the latter artifact have been ground, presumably for hafting.

\section{Burins $(N=3)$}

Although the burin blow was used as a truncating technique on a number of implements, true burins are limited to three specimens.

A crudely-worked 'bevelled-spall' burin (after Noone, 1934) has been fashioned from a thick chert flake (Fig. 5:g). No attempt has been made to thin the base, but the lateral margins are indented and have been ground. The proximal end has a projecting spur formed by the removal of spalls at acute angles to one another. Figure $5: \mathrm{h}$ is a 'convex-spalled' burin, also fashioned from a chert flake. A single vertical spall has been removed from one lateral edge, and a second arcing spall has been detached from the opposite margin, diagonal to the first. A third burin is a 'convex-scaled' specimen manufactured from quartzite. It has been bifacially retouched, and has had only a single burin spall removed. No edge grinding is discernible on the latter two specimens. 
Burin spall $(N=1)$

The recovery of only a single burin spall lends support to the idea that the burin industry is poorly represented at the Lagoon site. Neither intentional nor use retouch is apparent.

Burin-like tools $(N=2)$

Burin-like tools are thought to have served as functional equivalents of spalled burins in late Paleoeskimo contexts, so it is interesting to note the presence of both tool types in the Lagoon assemblage. The two burin-like tools have been fabricated from siltstone, shaped first by chipping and with subsequent face polish (Fig. 5:i). The proximal end of each has been ground into bevelled adze-like edges. The larger of these tools is $44.7 \mathrm{~mm}$ in length and $25.5 \mathrm{~mm}$ in width. The other is somewhat smaller, with a length of $25.6 \mathrm{~mm}$ and a width of $22.0 \mathrm{~mm}$, but is still large in comparison to other known burin-like tools. The lateral edges of both have been indented, but no attempt has been made to thin the bases of these tools.

Adzes $(N=3)$

The three tools in this category show considerable variability in workmanship and manufacture. Two have been fashioned from bifacially-chipped siltstone. One of these has been finished by secondary flaking along 3 edges (Fig. 5:k). The other has been ground at both ends, producing bevelled working edges (Fig. 5:j). A third specimen has been roughly fashioned from a quartzite decortation spall and exhibits discontinuous edge retouch only.

Side blades $(N=32)$

Blades designed for hafting into the lateral edges of tools can be grouped into three sub-categories:

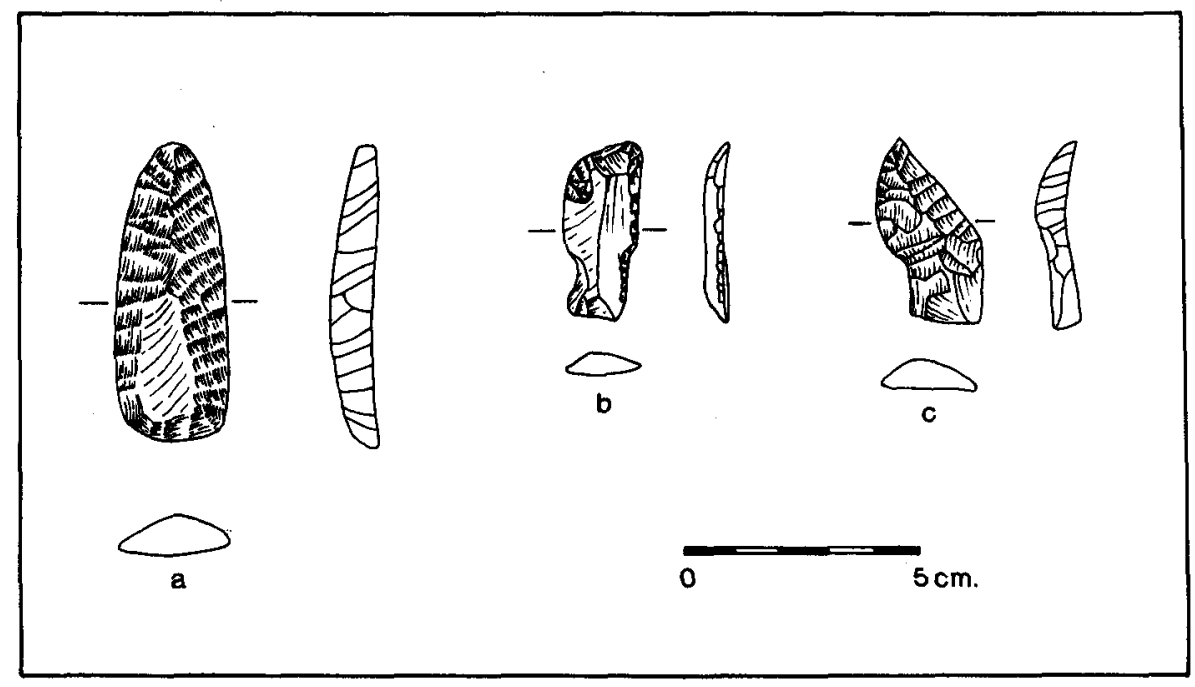

FIG. 6. Scraper varieties: $a$, end scraper; b, side scraper; $c$, transverse scraper. 
1. Asymmetric side blades $(\mathrm{N}=17)$

Four complete and 12 broken implements, tentatively identified as side blades for knives, have been fabricated by bifacial retouch of long and often thin flakes or blades. Most are characterized by straight bases, and one straight and one slightly convex lateral edge which meet in a blunt point (Fig. 7:1), although the outlines of some have been further modified through resharpening (Fig. 8:a). Battering and wear are most apparent on the convex edge. These tools are

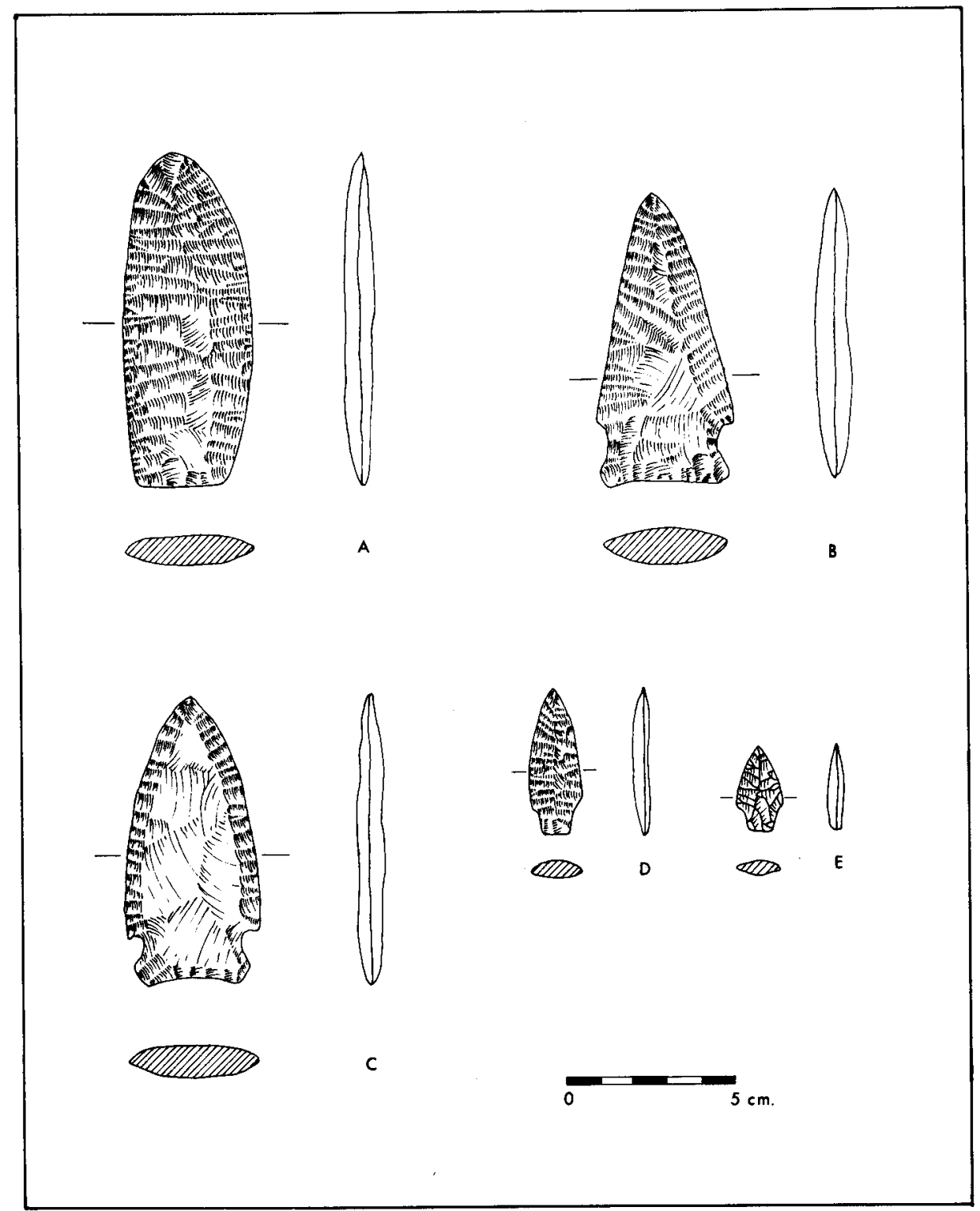

FIG. 7. Side (a) and end (b-e) blades. 
relatively large: the complete specimens range from $72.0 \times 36.0 \times 8.3 \mathrm{~mm}$ (length, width, and thickness respectively) to $98.1 \times 39.0 \times 8.2 \mathrm{~mm}$. Two of the fragments are $c a .58 \mathrm{~mm}$ in width, indicating that even larger artifacts are included in this group. With the exception of a chalcedony fragment, these asymmetric side blades have been manufactured from quartzite.

2. Ovate side blades $(\mathrm{N}=10)$

Two chert and eight quartzite bifaces which conform to an ovate shape (Fig. $8: b, c)$ are classified as side blades by inference rather than on the basis of direct evidence for hafting. They lack sharply-pointed tips, which suggests that the lateral edges were the essential parts of these tools. In the absence of any basal modification or edge-backing, it is likely that they were laterally inset into handles of some sort. These tools range from $43.8 \times 29.3 \times 5.2 \mathrm{~mm}$ to $110.2 \times$ $58.8 \times 11.1 \mathrm{~mm}$.

3. Bi-pointed side blades $(\mathrm{N}=5)$

These artifacts are also interpreted to have served as lateral insets as they lack hafting attributes diagnostic of end blades. Varying from $23.1 \times 13.8 \times 4.0 \mathrm{~mm}$ to $35.6 \times 14.9 \times 4.6 \mathrm{~mm}$, they are of a size which suggests their use on projectiles, although no such tools with provision for side blades were recovered. The four complete or nearly-complete specimens are bi-pointed, and are slightly asymmetric in curvature (Fig. 8:d,e). The fifth is damaged at both ends, but otherwise conforms in morphology.

\section{End blades $(N=56)$}

End-hafted blades comprise the largest category of chipped stone tools. They can be separated into several groups according to their particular hafting modifications.

1. Corner-notched end blades $(\mathrm{N}=1)$

A large quartzite end blade $85.2 \mathrm{~mm} \times 39.9 \mathrm{~mm} \times 7.3 \mathrm{~mm}$ has a gentlyindented base and two corner-removed notches (Fig. 7:c). The base has been thinned by removing a series of trimming spalls, and the margins along the notches have been heavily ground. The blade portion of this tool is symmetric in outline.

2. Side-notched end blades $(N=18)$

With a single exception, the artifacts in this sub-category have triangular bodies, side notches which have been heavily ground, and have been basally thinned (Fig. 7:b). The exception is a broken quartzite specimen which appears to have had an ovate body.

Eight complete or nearly complete specimens and four basal fragments, all of quartzite, are relatively large, ranging from 49.9 to $105.4 \mathrm{~mm}$ in length, and are slightly asymmetric in outline due to repeated sharpening along one edge (Fig. $8: \mathrm{f}$ ). Widths at the notches range from 21.4 to $34.7 \mathrm{~mm}$, indicating that they were hafted onto fairly wide handles or shafts. Lengths of the notches vary from 6.2 $\mathrm{mm}$ to $13.9 \mathrm{~mm}$, and indicate a demand for a stable blade-haft juncture. These attributes suggest that these artifacts were hafted as end-bladed knives, although the possibility that they served as tips for thrusting spears should not be discounted. 


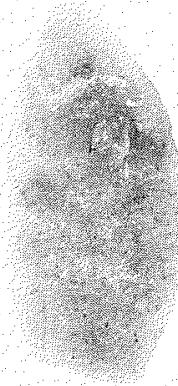

a
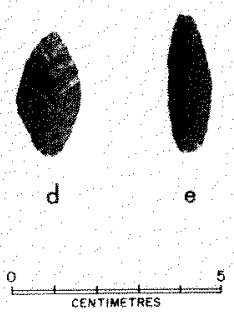

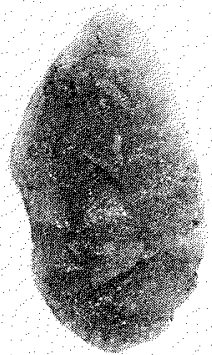

b
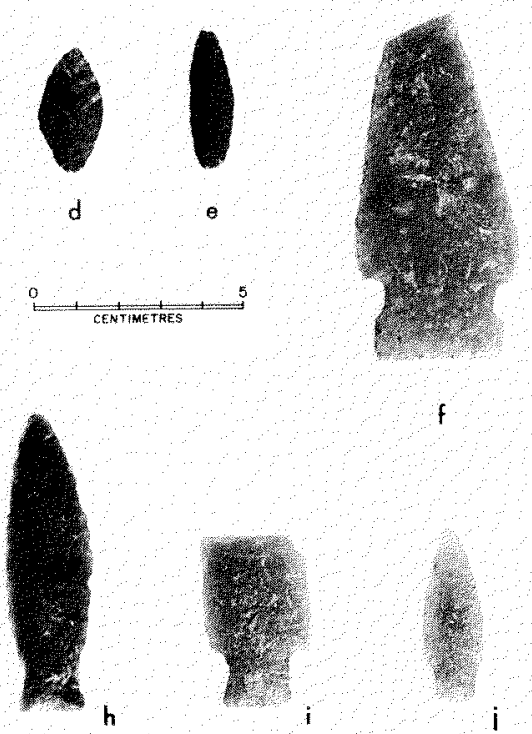

$f$

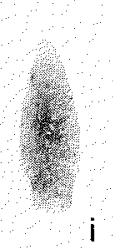

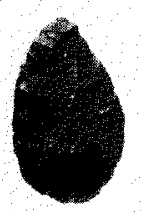

c

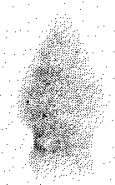

9

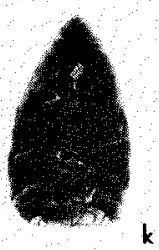

FIG. 8. Lithic artifacts: a-e, side blades; $f-k$, end blades.

Two additional end blades, one of quartzite and the other of basalt, exhibit similar characteristics but are somewhat smaller, and are more likely to have served as end blades for projectiles (Fig. 8:g). Three basal fragments, one of quartzite and two of chert, also fall within this smaller size category.

3. Fish-tail end blade $(\mathrm{N}=1)$

A constriction near the distal end and an indented base give this finely-worked chalcedony end blade a "fish-tail" appearance (Fig. 8:h). It is long (72.5 mm) and slender (maximum width is $20.4 \mathrm{~mm}$ ), but relatively thick in cross section $(8.0$ $\mathrm{mm})$. There is no evidence of edge grinding.

4. Stemmed end blades $(\mathrm{N}=25)$

Judging from breakage patterns and absence of wear, 9 complete and 15 broken stemmed end blades are likely to have been used to tip projectiles (Fig. $8: \mathrm{i}, \mathrm{j} ;$ Fig. $7: \mathrm{d}, \mathrm{e})$. The complete specimens range in length up to $49.1 \mathrm{~mm}$, and a few of the broken points may have been twice that length. These end blades are slender and rather thin in cross section. The stems taper only slightly towards the base and have been ground along their lateral margins. The basal ends of 19 of the 
specimens have been thinned, and are chisel-like in cross section (Fig. 7:d). Five others are similar in form, but exhibit no basal thinning (Fig. 7:e). The differences in the bases may be a function of hafting, the former having been fitted into weapons with slots and the latter held in beds or concavities (although, again, it should be pointed out that no shafts or foreshafts with slots were recovered). Six of these have been fashioned from chert, and the remainder from quartzite.

Also included in this category is the distal portion of a large, crudely-worked quartzite end blade with a tapering stem and a slightly indented base. The lateral margins of the stem have been lightly ground.

5. Triangular end blade $(\mathrm{N}=1)$

A single chert triangular end blade was recovered (Fig. 8:k). It measures 52.1 $\mathrm{mm} \times 31.3 \mathrm{~mm} \times 5.9 \mathrm{~mm}$, and has slightly convex lateral margins and a straight base. No edge grinding is apparent. Implements of this form have elsewhere been classified as end blades for harpoons (Giddings, 1964:233). However, the lateral margins of the Lagoon specimen exhibit continuous use retouch which may be an indication that it has been employed in cutting, rather than stabbing, activities.

6. Unclassifiable end blade fragments $(\mathrm{N}=10)$

Fragments of nine quartzite and one chert bifacially-worked artifacts may represent the proximal portions of broken end blades. The bodies of these implements are triangular, but as bases are lacking they cannot be grouped into any of the preceding categories.

Among the remaining chipped stone artifacts are miscellaneous bifaces $(\mathrm{N}=54)$, some of which are likely to have been preforms, while others are fragments of tools broken in manufacture, through use or post-depositionally. Flakes exhibiting use retouch $(\mathrm{N}=51)$ represent a small proportion of the several thousand pieces of stone debitage. Blades and bladelets $(\mathrm{N}=33)$ are likewise rare and none qualify as microblades. Five angular flake cores were found, and four core fragments which display blade scars.

The few non-chipped stone tools include:

Lamps $(N=5)$

Four sandstone cobbles or cobble fragments with basin-shaped depressions were recovered from the site (Fig. 9). The depressions are fairly shallow (14.0 $27.0 \mathrm{~mm}$ ), and have been pecked to shape, quite likely by enhancing what were originally natural depressions. A fifth specimen has been fashioned from mudstone, and has a ground-out basin. Similar implements recovered from Choris (Giddings 1957: 124-125) and Norton (Giddings 1964, Plates 58-60; Lutz 1972, Plates 44 and 45) deposits in Alaska have been described as oil lamps. Charred fat on three of the Lagoon specimens may indicate a similar function.

Hammerstones $(N=6)$

Six elongate pebbles exhibit end or side battering indicating that they have been used as hammerstones.

Whetstone $(N=1)$

This is a small abrasive sandstone pebble with scratched surfaces. 


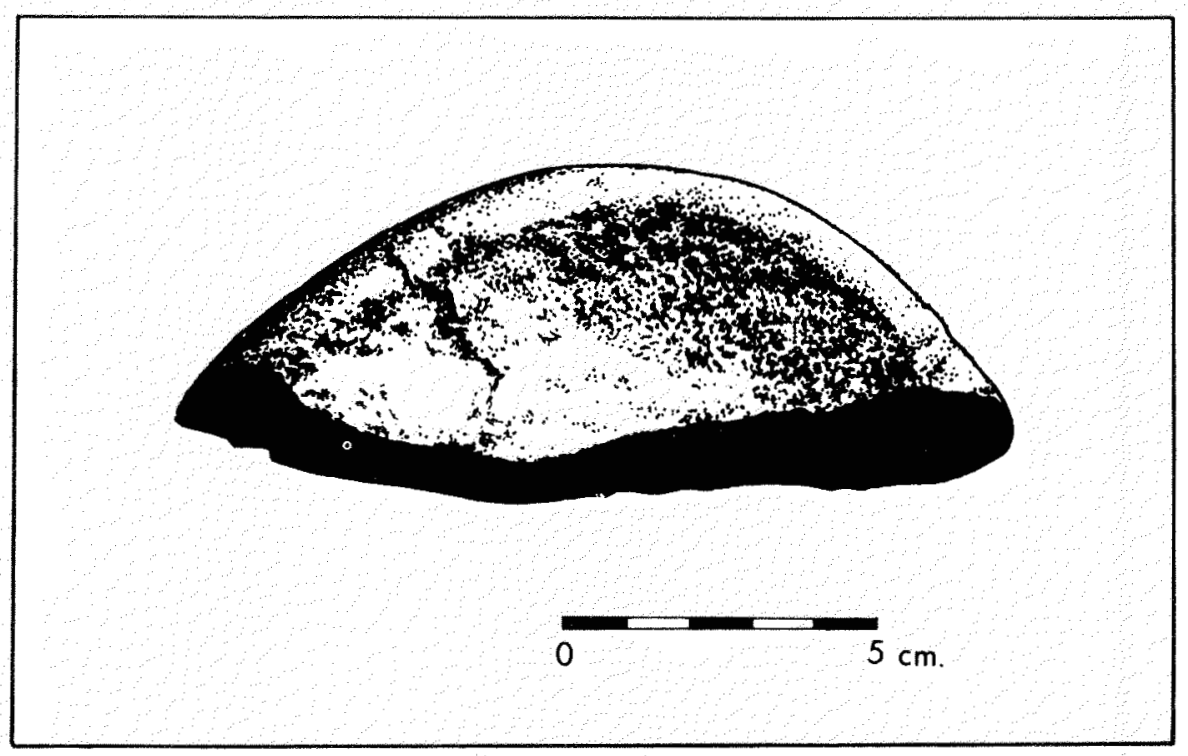

FIG. 9. Fragment of a stone lamp.

NON-LITHIC ARTIFACTS

The aridity of the soil, as well as the close proximity of the permafrost which underlie the cultural zone in most of the excavation units, aided in the preservation of a wide range of organic artifacts, which count for $38.3 \%$ of the total artifact sample.

\section{Harpoon heads $(N=9)$}

1. Unilaterally-barbed harpoon heads $(\mathrm{N}=1)$

Figure 10:b illustrates a small $(74.5 \mathrm{~mm}$ in length) self-pointed antler harpoon head. It has a single lateral toggling spur, and a single barb. A grooved line hole extends into the shallow shaft socket. The margins on either side of the socket have been scored, probably to facilitate lashing the harpoon head to a foreshaft. Although the surface of the artifact is badly deteriorated, 2 shallow incised lines can be discerned parallel to the line hole, immediately above the toggling spur.

2. Bilaterally-barbed harpoon heads $(N=4)$

These antler harpoon heads have wide, shallow, rectangular, open sockets with heavily-scored marginal indentations. Each has a single cut line hole, and the three almost complete specimens have single toggling spurs. All have been broken at their proximal ends. Two have a single remaining set of bilaterallyopposed barbs (Fig. 11:a), two have two sets (Fig. 10:a), and all four may have had more. A simple, incised line decoration is apparent on the better-preserved specimens. The largest harpoon head of this style was greater than $115 \mathrm{~mm}$ in length when complete, and the others may have approximated that size.

3. Miscellaneous barbed harpoon heads $(\mathrm{N}=2)$

A broken antler harpoon head shares a number of attributes with the bilaterally-barbed forms, but has only one lateral barb remaining. It has a shallow 
rectangular open socket, a gouged line hole, and incised line decoration. A second artifact, small and badly deteriorated, resembles the bilaterally-barbed harpoon heads in outline and may have been a toy.

4. End-bladed harpoon heads $(N=2)$

Figure 10:c is a small ( $85.2 \mathrm{~mm}$ in length) ivory harpoon head. It is triangular in cross section, and, in order to compensate for the resultant dorsal ridge, it has a slot on the dorsal surface in addition to a lateral indentation for securing the lashing which held the harpoon head to the foreshaft. Like the barbed specimens, it has a shallow, rectangular, open socket, single toggling spur, and a cut line hole. An open bed has been carved into the proximal end to hold an end blade, and the lateral margins at that point have been indented and scored. The surface of the artifact has been decorated with an incised line decorative motif (see also Fig. 12:d). A second specimen is similar (Fig. 10:d), but is oval in cross section and has a lashing slot near one lateral edge matched by an indentation on the opposite margin. The surface of this article is badly deteriorated, but traces of an incised line decoration are apparent.

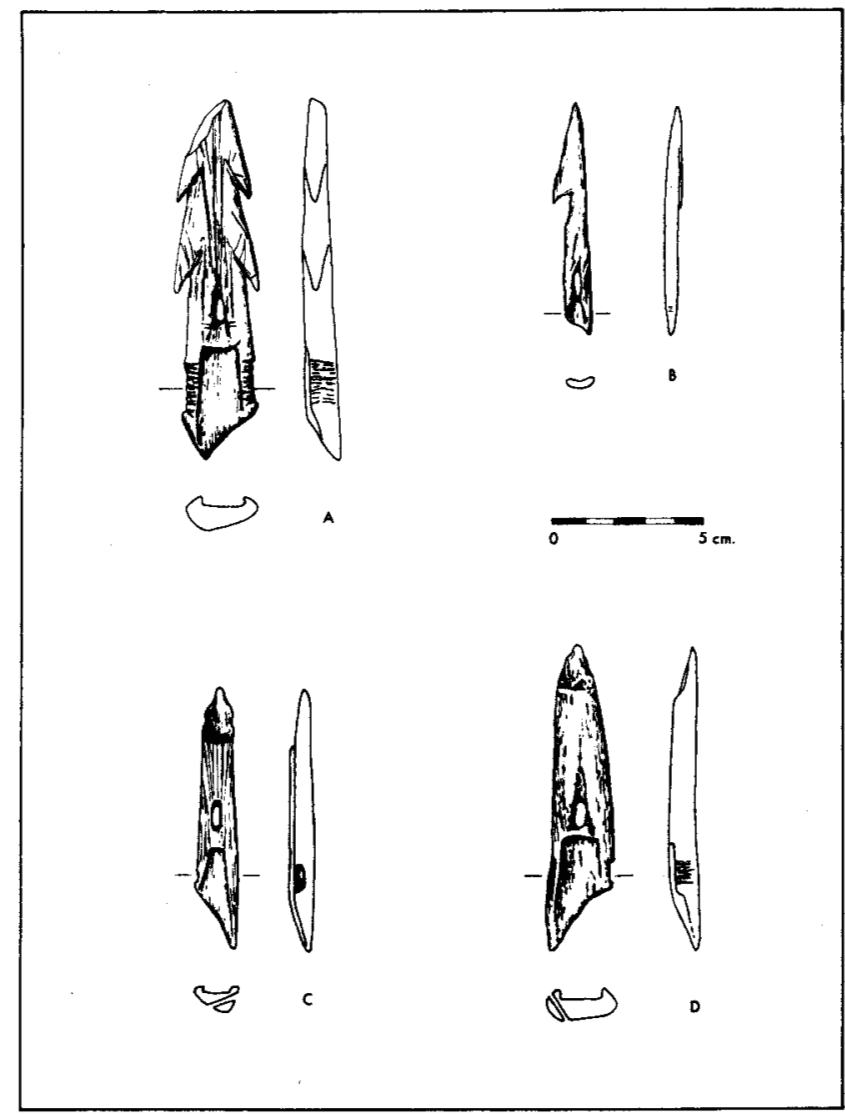

FIG. 10. Harpoon heads: barbed ( $a, b)$ and end-bladed ( $c, d)$ varieties. 


\section{Lance head $(\mathrm{N}=1)$}

This artifact, which in most respects is similar to the end-blade harpoon heads, has been classified as a lance head as it lacks a line hole (Fig. 11:b). It is apparently a finished form, as it exhibits damage which has likely resulted from use on either side of the centrally-placed spur. Like the harpoon heads, this implement has a wide and shallow rectangular open shaft socket, and has a bed for an end blade. The dorsal surface of the lance head has been decorated with incised lines (Fig. 12:e).

\section{Harpoon foreshafts $(N=2)$}

Figure $11: \mathrm{c}$ is an antler lance or harpoon foreshaft. It is $140.2 \mathrm{~mm}$ in length, and reaches a maximum width of $14.3 \mathrm{~mm} \mathrm{ca}$. two-thirds of the way down its length, from where it tapers to a narrow tip and a blunt, rounded butt. A laterally-offset line hole has been gouged below the midpoint. The tip of this specimen is too narrow to fit any but the small unilaterally-barbed harpoon head; however, a second foreshaft, represented by a portion of its proximal end only, is of a size and shape that fits snugly into the sockets of the other harpoon heads.

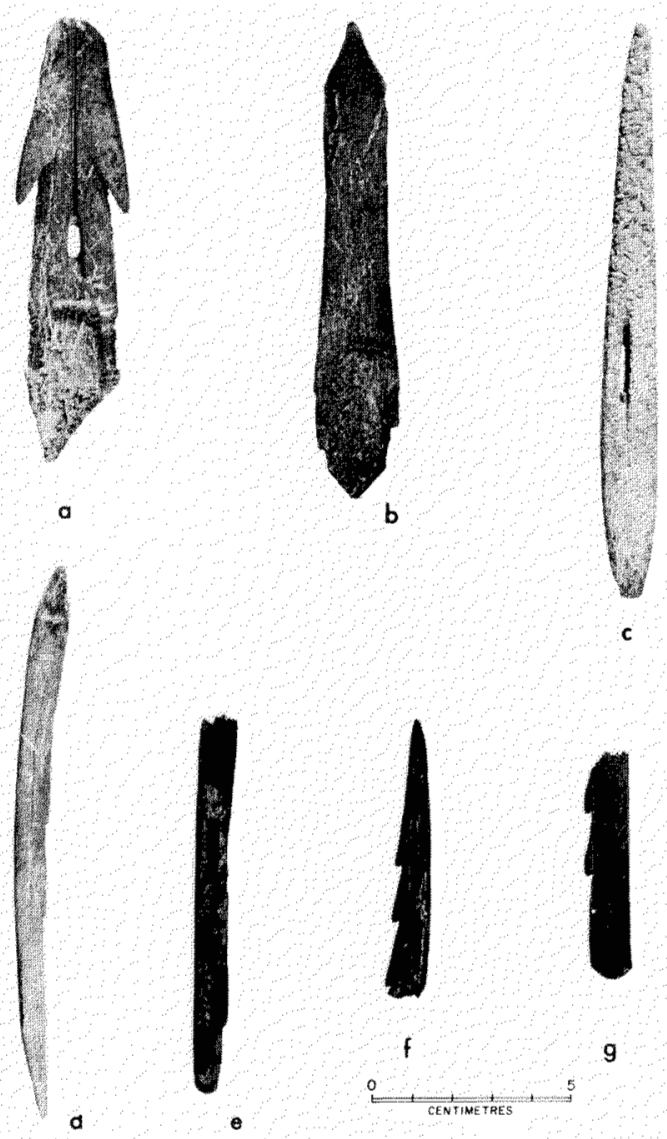

FIG. 11. Bone and antler artifacts; $a$, barbed harpoon head; b, lance head; $c$, foreshaft; $d, e$, end-bladed points; $f, g$, barbed points. 
Points $(N=14)$

1. Barbed points $(\mathrm{N}=3)$

A broken antler artifact with unilateral barbs and a sharply-pointed tip may have been the proximal part of a projectile point or leister prong (Fig. 11:f). Two basal portions of what may have been similar artifacts have rounded butts (Fig. $11: \mathrm{g})$. All three have been marked or decorated with longitudinal incisions.

2. End-bladed points $(\mathrm{N}=2)$

The antler point shown in Figure 11:d has a simple conical tang and a shallow bed for an end blade. Two seemingly non-functional barbs have been cut into one of the lateral margins. A similar artifact (Fig. 11:e) has been damaged at both ends. The latter specimen has been decorated by a geometric paired line motif.

3. Bi-pointed $(\mathbf{N}=2)$

Two antler artifacts which are circular in cross section, widest at the centre and tapering off to a point at either end may have served as projectile points, or as the central prongs of fish spears.

4. Unclassifiable fragments $(N=7)$

Among the unidentifiable artifacts in the assemblage are a number of broken antler and ivory objects which have pointed tips, but which lack diagnostic attributes which would allow them to be included in any of the preceding categories.
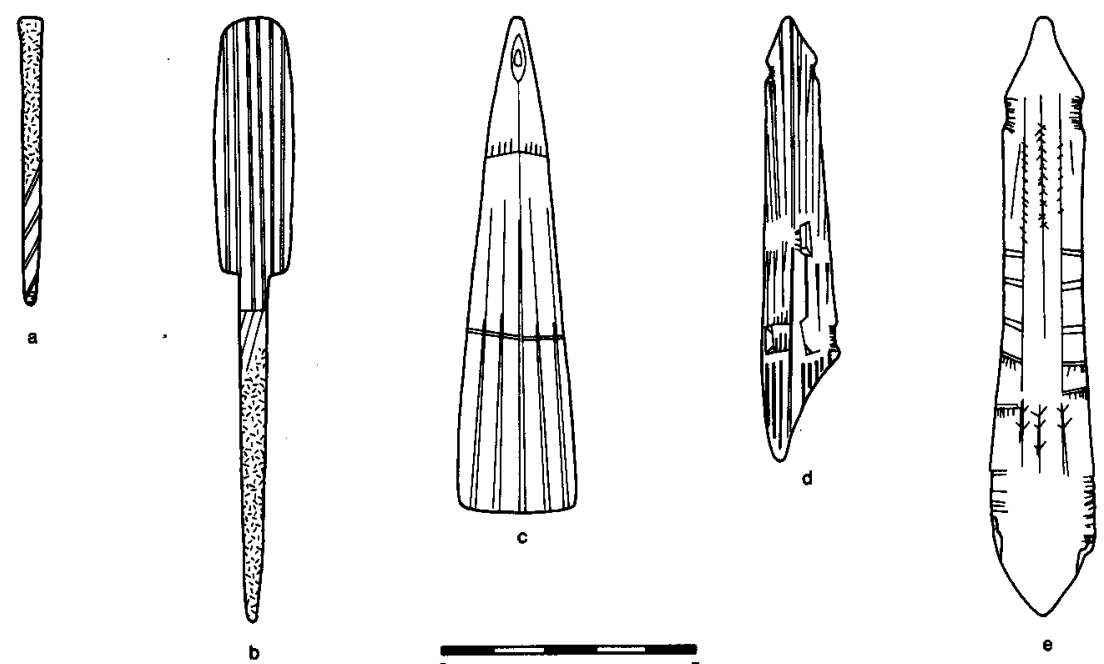

FIG. 12. Decorative motifs; a, engraving tool; b, awl; $c$, pendant; $d$, harpoon head; e, lance head. 


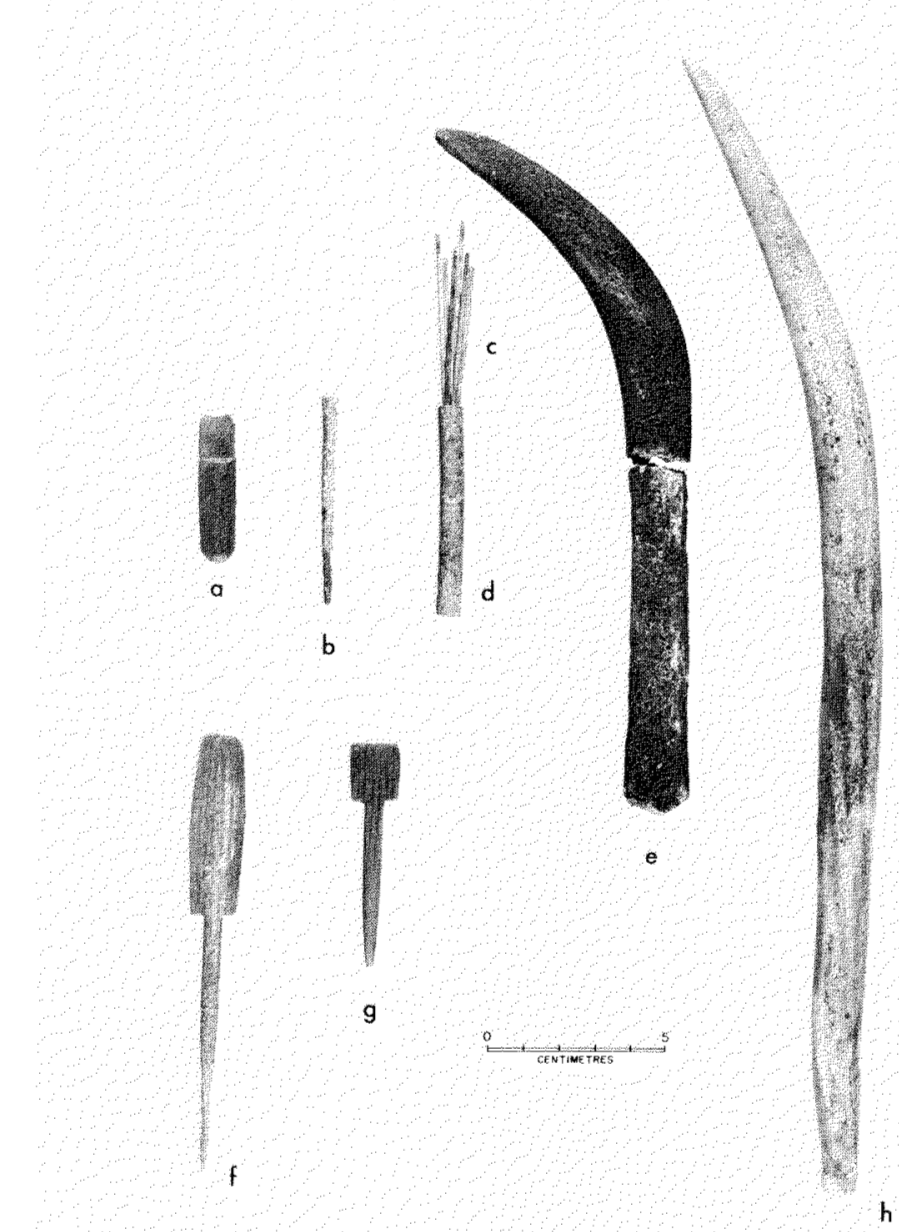

FIG. 13. Bone and antler artifacts; $a$, handle; $b$, engraving tool; $c$, needles; $d$, needle case; $e$, antler knife; f, $\mathbf{g}$, awls; h, flaker.

Haft $(N=1)$

Figure 13:a is a small ( $40.0 \mathrm{~mm}$ long) antler artifact with a rounded butt and a bed for an end blade. It quite likely served as a haft for a small stone point, burin, or similar tool.

\section{Engraving (?) tools ( $N=2$ )}

Two bone or antler artifacts are characterized by their 'nail-like' appearance, tapering from an expanded head to a blunt point (Fig. 13:b). The pointed ends have been grooved, and bear a series of circumferential incisions, and were likely fitted with stone or metal tips. Somewhat similar specimens from the Point Hope Ipiutak site (Larsen and Rainey, 1948: PI. 8:15-24) have been identified as engraving tools. However, if the paired line spiral motif engraved on the Lagoon specimens bears any relationship to the function of the tools (Fig. 12:a), they may have been used with rotary movements, possibly for drilling eyes in needles. 
Antler knives $(N=8)$

Several worked pieces of antler may have been used as snow knives, scrapers, or for some hide-working process. The only complete specimen (Fig. 13:e) is $190.2 \mathrm{~mm}$ in overall length. It has a straight handle and a curved blade which tapers to a tip. Both lateral margins of the blade have been polished smooth. The broken specimens were all somewhat larger.

Flaker $(N=1)$

Figure 13:h shows a long (ca. $210 \mathrm{~mm})$, curved antler object which tapers to a point at one end. The margins near the base have been slightly indented, and the surface at this point has a pronounced lustre, as if it had been wrapped with a thong (perhaps for suspension?). It has been suggested that this artifact is a flaker (R. LaBlanc, pers. comm. 1978). If used as such, the long shaft would have rested along the inside of the arm, providing leverage for pressure flaking stone tools.

Needles $(N=93)$

Needles and needle fragments were the most common artifacts at the Lagoon site. They have been manufactured from sections of bird long bones which have been sharpened to a point at one end and rounded at the other. The finished specimens have round eyes which have been produced by biconical drilling (Fig. 13:c). All specimens are rectangular or sub-rectangular in cross section. In addition to the complete needles, proximal end fragments, midsections and distal end fragments of broken specimens were found. Nineteen unfinished forms are also included in this category.

Needle blanks $(N=16)$

Sixteen long bone shafts of unidentified bird species have been scored by a series of longitudinal grooves. Similar worked bone pieces have elsewhere been interpreted as drinking tubes (Giddings, n.p.: 29; MacNeish 1959, Pl. 6:20), but in the view of the present context it seems likely that the specimens recovered from the Lagoon site are blanks representing an initial step in the production of needles.

Needle cases $(N=3)$

Six of the complete needles were found in situ in a needle case (Fig. 13:d). The case has been fashioned from a hollow section of bird bone $57.4 \mathrm{~mm}$ in length and $7.4 \mathrm{~mm}$ in diameter. Two similar artifacts were also recovered.

Awls $(N=9)$

Five complete artifacts as well as two proximal and two distal fragments are inferred to have been used as awls (Fig. 13:f,g), although similar artifacts have not been previously reported. This interpretation is based upon two observations: 1) the needles recovered from the site are unlikely to have been strong enough to penetrate thick hides, and 2) spiral line motifs on the points of two of the specimens may indicate that they were used in a twisting, perforating motion (Fig. 12:b). One of the artifacts in this category has a handle that is triangular in cross section, while the handles of the others are spatulate. All of the handles 
have been decorated with paired incised lines. It is also worth noting that the spatulate ends fit neatly within the shaft sockets of most of the harpoon heads, although I cannot comment on the significance of that correspondence.

Pendant $(N=1)$

A paired line motif similar in design and execution to those incised on the awls is also represented on an antler pendant (Fig. 12:c). It is triangular in outline, and attains a shallow ' $\mathrm{V}$ ' in cross section. A hole for suspension has been gouged at the narrow end.

$\operatorname{Bead}(N=1)$

This artifact has been fashioned simply by cutting off a section of hollow bird bone.

Miscellaneous worked bone and antler $(N=33)$

Various pieces of bone and antler which have been cut, grooved, polished, or otherwise worked are either broken or incomplete, rendering them unidentifiable.

Wood stakes $(N=4)$

Four pieces of wood, probably driftwood, have been sharpened to a point at one end, possibly to be used as stakes.

Bowl fragment $(N=1)$

A fragment of carved driftwood may have been the rim portion of a bowl or ladle. It appears to have been oval in outline, and to have had sloping sides.

$\operatorname{Skin} \operatorname{kamik}(N=1)$

An intact sealskin kamik or boot (Fig. 14) has an oval sole $c a .160 \mathrm{~mm}$ in length and $95 \mathrm{~mm}$ wide which has been stitched, hair side out, to an upper which has the hair side turned in. With the exception of a stitch up one side, no attempt has been made to shape or crimp the upper, and the sides of the kamik were apparently gathered about the ankle and secured with a leather thong. Patches of hair remaining on the sole lie toward the heel, and may have been left to provide traction when walking on ice.

Skin bag $(N=1)$

A bag or container $c a .200 \mathrm{~mm}$ long and $130 \mathrm{~mm}$ wide has been fashioned by folding over a single piece of sealskin and sewing up the seam. A flap hangs over one end, and two patches have been sewn on one side.

Lashings $(N=5)$

1. Leather thong $(\mathrm{N}=1)$

A short skin thong was found in close proximity to the kamik described above, and may be a part of that garment.

2. Knotted hair $(\mathrm{N}=2)$

Two short lengths of coarse black hair have been knotted. Although they have not been securely identified, the colour and coarseness indicate that the hair is from a muskox. 


\section{Knotted baleen $(\mathrm{N}=2)$}

Two baleen lashings were also recovered. One of these is a single knotted length, and the second represents the juncture of two such lengths.

\section{FAUNAL ANALYSIS}

Insights into the economic basis of the Lagoon site occupation and hints at the time of year during which that occupation took place can be gleaned from the faunal remains. Table 1 lists the identifiable bones collected from Area A by species and gives counts for each. Calculations of the minimum number of individuals are based upon the least number of individuals of each species that could be represented by the most frequently occurring skeletal elements in the sample. The relative frequencies (shown as percentages) may approximate the true proportions of the various species; however, food sharing, bone processing, canine scavenging and other activities are likely to have biased th sample to some degree.

Bird remains form the major part of the faunal assemblage. Of these, goose (Canada and Snow) predominate (Grant-Francis, 1979). Canada geese do not visit Banks Island today. Snow geese are normally present from early spring

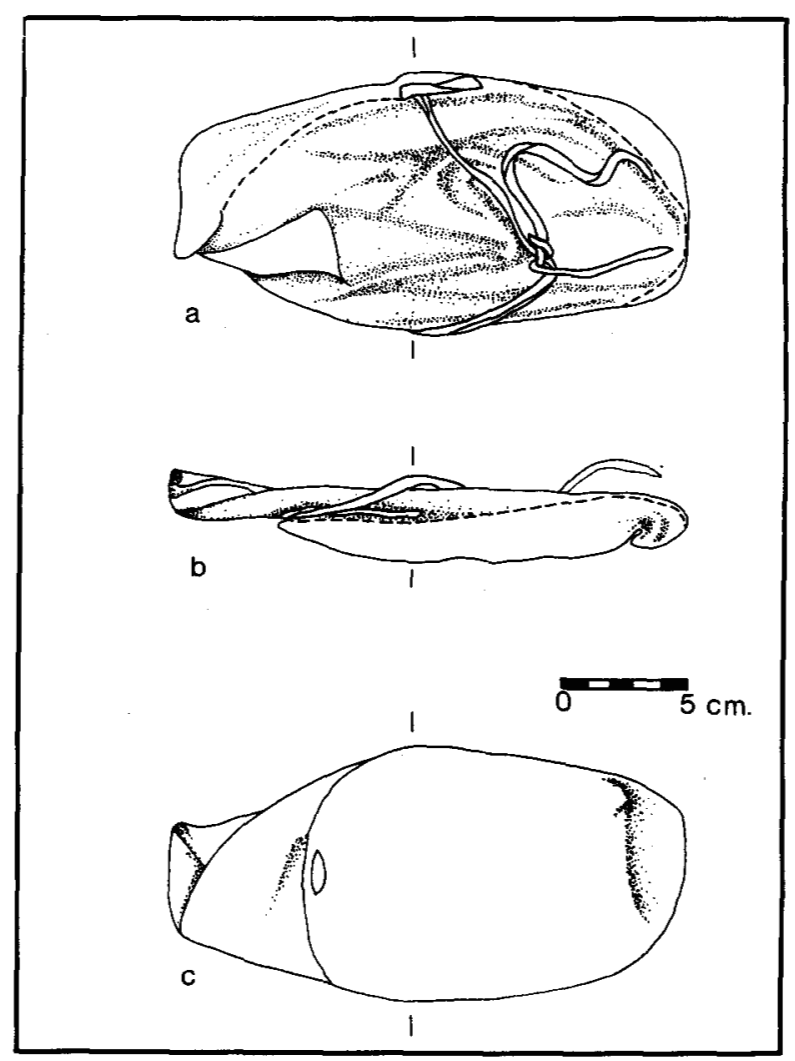

FIG. 14. Sealskin kamik. 
TABLE 1. Composition of the faunal assemblage from Area A

\begin{tabular}{|c|c|c|c|c|c|}
\hline \multirow[b]{2}{*}{ Species } & & \multicolumn{2}{|c|}{ total bones } & \multicolumn{2}{|c|}{$\begin{array}{l}\text { minimum } \\
\text { individuals }\end{array}$} \\
\hline & & $\#$ & $\%$ & \# & $\%$ \\
\hline goose & (Chen and Branta) & 318 & 37.4 & 33 & 35.5 \\
\hline ptarmigan & (Lagopus spp.) & 189 & 22.3 & 21 & 22.6 \\
\hline ringed seal & (Phoca hispida) & 183 & 21.5 & 12 & 12.9 \\
\hline muskox & (Ovibos moschatus) & 78 & 9.2 & 6 & 6.5 \\
\hline arctic fox & (Alopex lagopus) & 47 & 5.8 & 9 & 9.7 \\
\hline arctic hare & (Lepus arcticus) & 14 & 1.6 & 3 & 3.2 \\
\hline caribou & (Rangifer tarandus) & 4 & 0.5 & 2 & 2.2 \\
\hline lemming & (Dicrostonyx torquatus) & 4 & 0.5 & 1 & 1.1 \\
\hline canid & (Canis spp.) & 3 & 0.4 & 1 & 1.1 \\
\hline snowy owl & (Nyctea scandiaca) & 2 & 0.3 & 1 & 1.1 \\
\hline bearded seal & (Erignathus barbatus) & 1 & 0.1 & 1 & 1.1 \\
\hline fish & sp.? & 1 & 0.1 & 1 & 1.1 \\
\hline sandhill crane & (Grus canadensis) & 1 & 0.1 & 1 & 1.1 \\
\hline whistling swan & (Olor columbianus) & 1 & 0.1 & 1 & 1.1 \\
\hline & TOTAL & 846 & 99.9 & 93 & 100.3 \\
\hline
\end{tabular}

until late fall, but are particularly vulnerable during moult, a three to four week period commencing at about the middle of June with the onset of egg incubation (Manning et al., 1956). An early summer occupation is further suggested by the presence of medullary deposits in the bones of at least four of the geese. These are secondary calcium deposits which accumulate in the skeleton of females of certain species of birds during their period of reproductive activity, and which are drawn upon for the formation of eggshell (Taylor, 1970; Rick, 1975). No such deposits were found in the skeletons of any of the ptarmigan, which are yearround residents on the arctic tundra. This does not necessarily compromise the above hypothesis. Male ptarmigan began to moult early in June, several weeks earlier than do females (Weeden, 1963); therefore, males are more vulnerable early in the summer, and the faunal sample may be biased toward that gender.

Ringed seals are the most common mammalian species represented. Judging by the state of epiphyseal union, at least $40 \%$ of the individuals were immature when killed. This may be significant, as Smith (1973) has shown that, due to competitive pressures, mainly adults are procured when hunting at near-shore breathing holes, while ice-edge or open-water hunting increases the proportion of sub-adults. Hunting from boats can be tentatively ruled out by the lack of evidence for watercraft at this and other Paleoeskimo sites of comparable age. The high proportion of immature seals may therefore reflect ice-edge hunting. Although not restricted to any one period, open water leads are most frequent in late spring and early summer. The only contrary evidence is provided by the remains of three fetal seals, indicating hunting prior to the whelping season (normally, mid-March to mid-April). Without belabouring the point, it may be that some of the seals were killed earlier in the year, and cached for later use.

Calculations of the number of muskoxen may be unrealistically low. Much of the bone recovered had been smashed into small, unidentifiable fragments, and, 
since muskox bones are rich in grease and marrow, they may have been preferentially accorded this treatment. Among the remains that could be identified as muskox were crania of two yearlings of undetermined sex, and mandibles representing two sub-adults. The size of the horn cores and the state of dentition allow for fairly accurate age assessments and, since calving is restricted to the period from April until early May (Tener, 1965), the time of the year in which the individual animals were killed can be estimated. Comparing horn core size to Allen's (1913) measurements, one individual was about 18 months old if female, and several months younger if male. The other was either an 18-month male or a 24-month female. On the basis of these observations, activity at the site could have extended from late spring/early summer through to autumn, or could have been restricted to either period, depending upon the sex of the animals represented. The alternatives are narrowed down by the state of the dentition in the mandibles. The third molar in one mandible had erupted, but the tooth had not advanced far above the alveolus. This condition is slightly advanced over that noted for animals entering their third year (Tener, 1965: 64). The third molar of the second mandible is almost fully grown, but shows little wear. This correlates with Tener's (1965) description of animals entering their fourth year. Although these conditions are subject to variation, they lend some measure of support to the suggestion that the Lagoon site was occupied in late spring/early summer.

Several other aspects of the faunal assemblage are worth noting. A canid is represented by three vertebrae: the 12th and 13th thoracic and the 1st lumbar. Identification at the species level is impossible; however, the dorsal surface of the spinous processes of the three vertebrae are flattened, which may indicate that they are the remains of a pack dog (Arnold, 1979). As a final observation, a scapula of an immature whale was recovered from Area B. Knotted baleen from that part of the site may have come from the same animal. As there is nothing in the artifact inventory to indicate that whales were hunted, it is likely that the remains are those of a drift carcass.

\section{CHRONOLOGICAL AND CULTURAL AFFILIATIONS
OF THE LAGOON SITE}

Radiocarbon age determinations have been obtained for scapulae of 3 muskoxen excavated from Area A: $2320 \pm 120$ years (RL-765); $2290 \pm 120$ years (RL-766); and $2390 \pm 110$ years (RL-767).

The middle centuries of the first millenium B.C. were important ones as far as Paleoeskimo cultural dynamics in the western Canadian Arctic are concerned. In the several centuries before the period of occupation at the Lagoon site the Dorset culture had begun to appear in many parts of the Canadian Arctic. McGhee (1976) and Fitzhugh (1976) have postulated that Dorset evolved from a Pre-Dorset base in a 'core area' which includes the coasts bordering on the Foxe Basin-Hudson Strait, and from there spread by migration into areas that PreDorset groups had previously abandoned. Aspects of this core area model have been taken to task by Schledermann (1978). Some measure of support for the process is, however, provided by evidence from the western regions of the Canadian Arctic. Taylor's $(1967,1972)$ work at the Ekalluk River in southern 
Victoria Island provides a basis for reconstructing several episodes in the culture history of this part of the Arctic.

The earliest Ekalluk River Paleoeskimo phase is Pre-Dorset, represented in at least three sites which range in age from $3180 \pm 120$ years (I-2057) to $2880 \pm 105$ years (I-2058; Wilmeth, 1978). Stylistic and technological characteristics of these assemblages - including the tendency to utilize locally-available quartzite for stone tools, the de-emphasis on miniaturization of those tools, and the absence of microblades - indicate divergence from the Foxe Basin-Hudson Strait Pre-Dorset. Earlier occupations at Shoran Lake on Banks Island (Taylor, 1967; Müller-Beck, 1975) share a number of the distinctive Ekalluk River PreDorset traits, which may indicate that the development of the regional variant was under way as early as 3500 B.P. This variant appears to have had a relatively long life, as Gordon (1975) has postulated that Ekalluk River Pre-Dorset is related to sites on the adjacent mainland barrengrounds, where occupation may have persisted until 2700 B.P. or later.

Dorset remains were deposited at the Ekalluk River not long after that date (Taylor, 1967, 1972). The Ballentine site has radiocarbon dates of $2450 \pm 220$ B.P. (GSC-658) and $2220 \pm 140$ B.P. (GSC-640; Wilmeth, 1978). Harpoon heads in this and other Ekalluk River Dorset components correspond to Meldgaard's type states A-20 to A-22, which in the core area date between 2400 and 1850 B.P. (McGhee, 1976:33). On typological grounds, the Joss site on western Victoria Island (McGhee, 1971), the Newnham and Oxford sites southeast of the Ekalluk River, and the Bernard Harbour I site on the mainland across from Victoria Island (Taylor, 1972) all fit within this phase of Dorset.

Little, if any, continuity is evident in a comparison of the Pre-Dorset and Dorset of the Ekalluk River area. Instead, the high degree of stylistic differentiation is sufficient to suggest cultural replacement. Furthermore, unlike the Shoran Lake and Ekalluk River Pre-Dorset components, which display distinct regionalism, the Dorset remains that are found in the western regions of the Canadian Arctic compare closely with contemporaneous developments in the Foxe Basin-Hudson Strait region, and very likely represent movements from that direction.

In summary, a regional variant of Pre-Dorset appears to have developed over a broad area in the western part of the Canadian Arctic as early as 3500 B.P. This variant may have persisted longest on the barrengrounds, but had apparently disappeared by 2500 B.P. More than one archaeologist has attempted to explain the demise of Pre-Dorset outside of the core area (Gordon, 1975; Fitzhugh, 1976), but a compelling argument has yet to be advanced. Soon afterwards, the coasts of that region were occupied by Dorset migrants who had penetrated the area from the east. However, yet another variable has to be incorporated into this scenario: excavations at Engigstciak (MacNeish, 1956a; 1956b) and Trout Lake (Gordon, 1970) in the northern Yukon, and at Kittigazuit in the Mackenzie delta (McGhee, 1971; 1974), have yielded assemblages seemingly affiliated with the Norton tradition (Dumond, 1977). The data are sparse, but nonetheless attest to an expansion of Alaskan Paleoeskimo into the western Canadian Arctic at about the time that the Lagoon site was occupied. 
The position of the Lagoon site within this framework, and indeed within the Paleoeskimo continuum as a whole, is not immediately obvious - at least when assessed on the basis of artifact comparisons. Certain of the implements found in the Lagoon assemblage, such as the 'awls' and the composite points with vestigial barbs, have not been reported from other sites. Others have widespread, if sporadic, distribution in Paleoeskimo complexes, reflecting ultimate connections and common adaptations. The flake knives, end scrapers, adze blades, and small lateral insets fall into this category. Certain of the traits, however, may be useful in assessing cultural affiliations.

Assuming that the $\mathrm{C}^{14}$ dates are realistic, the occupation at the Lagoon site coincides with the period of Dorset expansion into the western Canadian Arctic, and various aspects of the assemblage appear to be characteristic of Dorset. These include side-notching as an attribute, and, more specifically, certain forms of side-notched tools such as side and end scrapers (cf. Collins, 1950, Pl. IX, 13-15, 19-22); ground burin-like tools, which are found in a few Pre-Dorset contexts (cf. Taylor, 1967, Fig. 11:o) but which are more common in Dorset; antler 'knives' (cf. Helmer, n.p., Pl. 5: $a^{\prime}$, e'); and the lance head with open bed for an end blade (Taylor, 1968, Fig. 23:b). In addition, the engraving tools may have a functional equivalent in a specimen recovered from a Dorset site at Cresswell Bay (Taylor and McGhee, 1979, Pl. 13:h).

Despite these correspondences, a Dorset 'flavour' does not permeate the entire assemblage. Typically Pre-Dorset are the spalled burins [although a few early Dorset occurrences may be noted (cf. Collins, 1956, PI. VI: 1-12)]; needles with rounded heads and circular eyes (cf. Meldgaard, 1962, Pl. 5); and stemmed end blades (cf. Meldgaard, 1962, Pl. 5). The harpoon heads, while not typically Pre-Dorset, do display Pre-Dorset attributes. The Lagoon specimens all have open shaft sockets and single toggling spurs; these are common Pre-Dorset traits, although they also occur in late Dorset contexts (Maxwell, 1976: 59-67). Bilaterally-barbed harpoon heads also are well represented in Pre-Dorset (Maxwell, 1976: 60), whereas in Dorset this attribute is found only on lance heads (Taylor, 1967, Fig. 9:h; McGhee, 1976, Fig. 6:e). Other harpoon head attributes are more ambiguous. Open beds for end blades appear in Danmark Fjord Independence II (Knuth, 1967:37, and Pl. 6:1) and in sites on the $24 \mathrm{~m}$ level at Jens Munk Island (M2403-88); these contexts appear to represent transitional Pre-Dorset/Dorset situations. And while the lack of miniaturization applied to the manufacture of stone tools and the absence of a microblade industry may be a function of the use of quartzite as a raw material, these traits are also characteristic of Ekalluk River Pre-Dorset, and may represent a link with that variant. If so, this would imply a persistence of Pre-Dorset in the western Canadian Arctic for several centuries after it is generally thought to have terminated.

On a final note, since the occupation at the Lagoon site also coincided with the postulated eastward push of Alaskan Paleoeskimo, the possible effects of such a movement on cultures in the western Canadian Arctic shoud be considered. Traits shared between the Lagoon assemblage and Norton components, but not reported elsewhere in the Canadian Arctic, include crude stone lamps (cf. Giddings, 1964, Pls. 58-60; Lutz 1972, Pls. 44 and 45), certain decorative motifs, 
including paired line spirals (Giddings, n.p., Fig. 65:b), and lashing slots, noted on a harpoon head from a site near Wales (Giddings, n.p., Fig. 65:a). This attribute is also characteristic of Near Ipiutak and Ipiutak specimens (Larsen and Rainey, 1948, Pls. 13 and 78:1, 2, 4), as are open sockets and single toggling spurs. Correspondence can also be found in Norton and related complexes for some of the traits already compared to Canadian Arctic Paleoeskimo, including engraving tools (Giddings, 1964, Pl. 37: 11-13), stemmed end blades (cf. Giddings, 1964, Pl. 49), ground burin-like tools (Giddings, 1964: Pl. 41:b), and needles with rounded heads and circular eyes (cf. Giddings, 1957: Fig. 4:3).

In summary, the nature of the assemblage can best be described as eclectic. Furthermore, existing typological-historical frameworks are unlikely to satisfactorily account for the cultural affiliations of the assemblage unless antecedent events can be identified which could have caused the apparent deviation from the developmental trends of better known Paleoeskimo complexes.

\section{CONCLUSIONS}

The Lagoon site has provided additional information regarding cultural adaptation in the Canadian Arctic during the Paleoeskimo period. As could be expected, the data serve to pose new questions, one of the most intriguing of which concerns the cultural affiliation of the people that occupied the site. Factors which may have been responsible for the seemingly eclectic nature of the artifact assemblage probably cannot be systematically explored until such time as additional research into the Paleoeskimo prehistory of the western Canadian Arctic has been carried out. Notwithstanding this caveat, several alternative processes can be singled out for consideration:

It is conceivable that the comparisons noted are spurious, and reflect regional variation rather than cultural continuities. In that event, the question of cultural identification remains unanswered. On the other hand, a 'transitional' PreDorset/Dorset position would account for some of the anomalies. If so, the hints at an Ekalluk River brand of Pre-Dorset would argue for an in situ transition in the western Canadian Arctic; this idea would not negate a significant 'core area' input - in fact, the local archaeology would argue for that kind of diffusion if a persistence of Pre-Dorset in the western Canadian Arctic could be demonstrated. Assuming for the moment that persistence and diffusion did occur, influences from Alaskan Paleoeskimo should also be considered. Elsewhere, a 'hybridization' model of this kind based upon demographic processes has been outlined (Arnold, i.p.). Briefly stated, the model supposes for various reasons that under conditions of low population density - such as would characterize relict populations as well as pioneering groups - the permeability of cultural boundaries would be increased. While diffusionist models might not accommodate the additional data that are likely to be forthcoming, such a model should be fruitful in stimulating research. Nonetheless, I would argue that interaction resulting in cultural hybridization was and is a common process. In most cases, however, the participant components are likely to have been sufficiently alike 
that the resulting archaeological manifestations simply are not recognized as such. The Lagoon site, lying at the spatial and temporal boundaries of at least two distinct cultures, may be an exception that demonstrates the rule.

\section{ACKNOWLEDGEMENTS}

Funding for the Banks Island Archaeological Research Programme in 1976-77 was provided by the Arctic Institute of North America with the assistance of the Firestone Foundation, the Department of Indian Affairs and Northern Development, Imperial Oil Ltd., and the University of Calgary through the Thesis Research Grant Programme. Logistic support was provided by the Polar Continental Shelf Project.

\section{REFERENCES}

ALLEN, J.A. 1913. Ontogenetic and other variations in muskoxen, with a systematic review of the muskox group, recent and extinct. Memoirs of the American Museum of Natural History 1(4):103-226.

ARNOLD, CHARLES D. 1978. The Lagoon site (OjR1-3): Implications for Paleoeskimo interactions. Unpublished Ph.D. dissertation, University of Calgary.

1979. Possible evidence of domestic dog in a Paleoeskimo context. Arctic 32(3): 263-65.

i.p. Demographic process and culture change: An example from the western Canadian Arctic. University of Calgary Archaeology Association Publications.

COLLINS, H.B. 1950. Excavations at Frobisher Bay, Baffin Island, N.W.T. National Museum of Canada Bulletin 118:18-43.

1956. The T-1 site of Native Point, Southampton Island. N.W.T. Anthropological Papers of the University of Alaska 4(2): 63-89.

DUMOND, D.E. 1977. The Eskimos and Aleuts. London: Thames and Hudson.

FITZHUGH, WILLIAM. 1976. Environmental factors in the evolution of Dorset culture: a marginal proposal for Hudson Bay. In: Maxwell, M.S. (ed.) Eastern Arctic Prehistory: Paleoeskimo Problems. Society for American Archaeology. Memoir 31:103-118.

GIDDINGS, J.L. 1957. Round houses in the western Arctic. American Antiquity 23:121-135. 1964. The archaeology of Cape Denbigh. Providence: Brown University Press.

n.p. Archaeological and physiographic investigations in the Kotzebue Sound. Manuscript on file with the Arctic Institute of North America. Calgary, Alberta T2N IN4.

GORDON, BRYAN C. 1970. Recent archaeological investigations on the Arctic Yukon coast (including a description of the British Mountain complex). In: Smith, R.A. and Smith, J.W. (eds.) Early Man and Environments in Northwest North America. University of Calgary Archaeology Association, Calgary. pp. 67-86.

.1975 . Of men and herds in Barrenland prehistory. Archaeological Survey of Canada. Mercury Series Paper 28. Ottawa.

GRANT-FRANCIS, D. 1979. Identification of goose bones from the Lagoon site (OjR1-3), Banks Island, N.W.T. by discriminant analysis. Unpublished M.Sc. thesis, University of Calgary.

HELMER, JAMES. n.p. Report of the 1978 Karluk Island Archaeology Project. Manuscript on file with the Arctic Institute of North American. Calgary, Alberta T2N 1N4.

KNUTH, EIGIL 1967. Archaeology of Musk-Ox way. Etudes Pratiques de Hautes Etudes. Sorbonne. Centre d'Etudes Arctiques et Finno-Scandinaves, Contributions 5.

LARSEN, H. and RAINEY, F. 1948. Ipiutak and the Arctic whale hunting culture. American Museum of Natural History, Anthropological Papers 42.

LEVITT, J. 1976. The traceological method: An introduction and case study analysis of some late prehistoric hide-scraping tools from the Northwest Plains. Unpublished M.A. thesis, University of Calgary.

LUTZ, BRUCE. 1972. A methodology for determining regional intra-cultural variation within Norton, an Alaskan archaeological culture. Unpublished Ph.D. dissertation, University of Pennsylvania.

MANNING, T.H., HOHN, E.D. and MacPHERSON, A.H. 1956. The birds of Banks Island. National Museum of Canada Bulletin 143.

MAXWELL, MOREAU S. 1976. Pre-Dorset artifacts: The view from Lake Harbour. In: Maxwell, M.S. (ed.). Eastern Arctic Prehistory: Paleoeskimo Problems. Society tor American Archaeology, Memoir 31:58-78. 
MacNEISH, RICHARD S. 1956a. The Engigstciak site on the Yukon Arctic coast. Anthropological Papers of the University of Alaska 4(2):91-111.

1956b. Archaeological reconnaissance of the delta of the Mackenzie River and Yukon coast. National Museum of Canada Bulletin 142: 46-81.

1959. Men out of Asia: As seen from the northwest Yukon. Anthropological Paper. University of Alaska 7(2): 41-70.

McGHEE, R. 1971. Excavations at Kittegazuit. The Beaver. Autumn 1971: 34-39.

1974. Beluga hunters: An archaeological reconstruction of the history and culture of the

MacKenzie Delta Kittegarymiut. Newfoundland and Social and Economic Studies No. 4.

1976. Paleoeskimo occupations of central and high arctic Canada. In: Maxwell, M.S. (ed.).

Eastern Arctic Prehistory: Paleoeskimo Problems. Society of American Archaeology, Memoir : 31: $15-39$.

MELDGAARD, JORGEN. 1962. On the formative period of Dorset culture. In: Campbell, John (ed.). Prehistoric Cultural Relations between the Arctic and Temperate Zones of North America. Arctic Institute of North America Technical Paper 11:92-95.

MÜLLER-BECK, HANSJURGEN. 1975. Preliminary report on excavations at the site Umingmak in 1970 and 1973 by the Institute of Prehistory, Tubingen. Report on file with the Archaeological Survey of Canada, Ottawa.

NOONE, H.V.V. 1934. A classification of flint burins or gravers. Journal of the Royal Anthropological Institute of Great Britain and Ireland 64:81-92.

REIGAR, S. 1975. Arctic soils. In: Ives, J.D. and Barry, R.G. (eds.). Arcticand Alpine Environments. London: Methuen and Co. pp. 749-769.

RICK, ANNE M. 1975. Bird medullary bone: a seasonal dating technique for faunal analysis. Canadian Archaeological Association Bulletin 7: 183-190.

SCHLEDERMANN, PETER. 1978. Prehistoric demographic trends in the Canadian High Arctic. Canadian Journal of Archaeology 2:43-58.

ARNOLD, C.D. and SHANK, C.C. 1975. Archaeological site survey and excavations on Banks Island, N.W.T. Report on file with the Arctic Institute of North America, Calgary. Calgary.

SMITH, T.G. 1973. Population dynamics of ringed seal in the Canadian Eastern Arctic. Fisheries Research Board, Bulletin 181.

STEENSBY, H.P. 1916. An anthropogeographical study of the origin of the Eskimo culture. Meddelelser om Gronland 53:39-228.

TAYLOR, T.G. 1970. How an eggshell is made. Scientific American 222(3): 88-95.

TAYLOR, W.E., Jr. 1967. Summary of archaeological field work on Banks and Victoria Islands, Arctic Canada, 1965. Arctic Anthropology 4(1):221-243.

1968. The Arnapik and Tyara sites: An archaeological study of Dorset culture origins. Society for American Archaeology, Memoir 22.

1972. An archaeological survey between Cape Parry and Cambridge Bay, N.W.T., Canada. Archaeological Survey of Canada, Mercury Series, Paper 1.

TAYLOR, W.E., Jr. and McGHEE, R. 1979. Archaeological material from Creswell Bay, N.W.T., Canada. Archaeological Survey of Canada, Mercury Series, Paper 85.

TENER, J.S. 1965. Muskoxen in Canada, a biological and taxonomical review. Canadian Wildlife Service, Ottawa.

WEEDEN, R.B. 1963. Management of ptarmigan in North America. Journal of Wildlife Management 27:673-683.

WILMETH, ROSCOE 1978. Canadian archaeological radiocarbon dates (revised edition). Archaeological Survey of Canada, Mercury Series, Paper 77. 